\title{
Effects of rainfall patterns on annual plants in Horqin Sandy Land, Inner Mongolia of China
}

\author{
YUE Xiangfei ${ }^{1,2^{*}}$, ZHANG Tonghui $^{1}$, ZHAO Xueyong ${ }^{1}$, LIU Xinping ${ }^{1}$, MA Yunhua ${ }^{1,2}$ \\ ${ }^{1}$ Cold and Arid Regions Environmental and Engineering Research Institute, Chinese Academy of Sciences, Lanzhou 730000, \\ China; \\ ${ }^{2}$ University of Chinese Academy of Sciences, Beijing 100049, China
}

\begin{abstract}
Growth of annual plants in arid environments depends largely on rainfall pulses. An increased understanding of the effects of different rainfall patterns on plant growth is critical to predicting the potential responses of plants to the changes in rainfall regimes, such as rainfall intensity and duration, and length of dry intervals. In this study, we investigated the effects of different rainfall patterns (e.g. small rainfall event with high frequency and large rainfall event with low frequency) on biomass, growth characteristics and vertical distribution of root biomass of annual plants in Horqin Sandy Land, Inner Mongolia of China during the growing season (from May to August) of 2014. Our results showed that the rainfall patterns, independent of total rainfall amount, exerted strong effects on biomass, characteristics of plant growth and vertical distribution of root biomass. Under a constant amount of total rainfall, the aboveground biomass (AGB), belowground biomass (BGB), plant cover, plant height, and plant individual and species number increased with an increase in rainfall intensity. Changes in rainfall patterns also altered the percentage contribution of species biomass to the total $A G B$, and the percentage of $B G B$ at different soil layers to the total BGB. Consequently, our results indicated that increased rainfall intensity in future may increase biomass significantly, and also affect the growth characteristics of annual plants.
\end{abstract}

Keywords: Horqin Sandy Land; annual plants; rainfall patterns; biomass; plant growth

Citation: YUE Xiangfei, ZHANG Tonghui, ZHAO Xueyong, LIU Xinping, MA Yunhua. 2016. Effects of rainfall patterns on annual plants in Horqin Sandy Land, Inner Mongolia of China. Journal of Arid Land, 8(3): 389-398. doi: 10.1007/s40333-016-0044-5

Water availability is a key driving factor in ecosystem processes in water-limited regions (Noy-Meir, 1973; Huxman et al., 2004; Loik et al., 2004; Lauenroth and Bradford, 2009). The size of precipitation event is an important factor in arid-land ecology, and the pulse duration of moisture in the upper soil layer triggered by a precipitation event depends largely on the pulse size and the evaporative demand of the atmosphere (Sala et al., 1981; Weltzin et al., 2003; Lauenroth and Bradford, 2009). In arid and semi-arid regions, most of the rainfall events are less than $10 \mathrm{~mm}$, and the inter-annual variation of rainfall is caused mainly by those large events with low frequency (Sala and Lauenroth, 1982; Loik et al., 2004; Cheng et al., 2006). For example, in short-grass steppe, $70 \%$ of small rainfall events $(\leq 5 \mathrm{~mm})$ contributed $25 \%$ to the total rainfall during the growing season, while $7 \%$ of large events $(>20 \mathrm{~mm}$ ) contributed $35 \%$ to the total (Sala and Lauenroth, 1982). Small rainfall usually evaporates rapidly and only wets the surface soil, which exerts a limited influence on plant growth; by contrast, large rainfall stimulates plant growth because it can recharge water to the soil at a certain depth (Huxman et al., 2004; Thomey

*Corresponding author: YUE Xiangfei (E-mail: yuexf06@126.com)
Received 2015-09-16; revised 2015-12-28; accepted 2016-01-15
(C) Xinjiang Institute of Ecology and Geography, Chinese Academy of Sciences, Science Press and Springer-Verlag Berlin Heidelberg 2016 
et al., 2011).

As a consequence of global warming, rainfall regimes are changing (IPCC, 2007). The changes in most regions include increases in the variability of total rainfall, decreases in the number of rain days, and increases in the intensity of rainfall (IPCC, 2007; Allan and Soden, 2008). These changes are expected to significantly affect the structure and function of terrestrial ecosystems (Knapp et al., 2002; Fay et al., 2003; Cleland et al., 2013), especially in water-limited regions (Loik et al., 2004; Schwinning and Sala, 2004; Knapp et al., 2008). Consequently, an increased understanding of how rainfall variability affects vegetation characteristics is necessary to better predict the potential responses of ecosystems to rainfall regimes in future. Previous studies about the effects of rainfall variability on ecosystems focused mostly on the inter-annual variability in rainfall amount; however, there were few studies on the changes in the size and frequency of rainfall events under constant total amount of rainfall (Heisler-White et al., 2008, 2009; Midara et al., 2009).

Annual plants are the primary component of vegetation in arid and semi-arid regions, and have important ecological functions in the conservation and restoration of ecosystems. For understanding how different rainfall event sizes and frequencies affect the annual plants, we conducted a field experiment with simulated rainfall patterns (e.g. small rainfall event with high frequency and large rainfall event with low frequency) under a constant total amount of rain during the growing season of 2014. We hypothesized that: (1) the mean size and frequency of rain events will significantly affect the growth of annual plants independent of total amount of rainfall; (2) large rainfall event with low frequency will exhibit a higher rainfall use efficiency (RUE) than the small rainfall event with high frequency; and (3) the change in rainfall regimes will affect species diversity and composition of annuals.

\section{Materials and methods}

\subsection{Study area}

This study was carried out at Naiman Desertification Research Station $\left(42^{\circ} 55^{\prime} \mathrm{N}, 120^{\circ} 42^{\prime} \mathrm{E} ; 360 \mathrm{~m}\right.$ asl), Chinese Academy of Sciences, which is located in the southwestern Horqin Sandy Land, eastern Inner Mongolia, China. The area is characterized by a semi-arid continental temperate monsoonal climate, with windy and dry winter and spring, warm and relatively rain-rich summer, and short and cool autumn. Annual mean temperature is $6.4^{\circ} \mathrm{C}$, with the minimum monthly mean of $-13.1^{\circ} \mathrm{C}$ in January and the maximum of $23.7^{\circ} \mathrm{C}$ in July. The annual mean wind velocity ranges from 3.2 to $4.1 \mathrm{~m} / \mathrm{s}$ (Zhu and Chen, 1994). Mean annual precipitation from 1971 to 2013 was 342 $\mathrm{mm}$, and $60 \%-80 \%$ of total precipitation occurs during May-August (Fig. 1a). During the growing season, about $58.7 \%$ of rainfall events are $\leq 5 \mathrm{~mm}$ and they only occupy $12.6 \%$ of the total rainfall amount, while $9.6 \%$ of large events with rainfall $>20 \mathrm{~mm}$ account for $45.0 \%$ of the total (Fig. 1b). Mean annual potential evaporation is about $1,935 \mathrm{~mm}$. Soils in the study area are classified as sandy chestnut soil (Su et al., 2006). Common species of native annual plants include Chenopodium acuminatum, Artemisia scoparia, Corispermum macrocarpum, Setaria viridis, Chloris virgata and Salsola pellucida.

\subsection{Experimental treatments}

The simulated rainfall experiment was applied from 1 May to 8 August 2014, and conducted under a rain shelter $(10 \mathrm{~m} \times 5 \mathrm{~m})$ made of a steel frame supporting a transparent roof. Shelter sides remained open always to maximize air movement. Inside, 28 PVC buckets with $30-\mathrm{cm}$ inside diameter and 40-cm height for each were filled with homogenized soils. The soil seed bank was from a fixed sand dune of the Naiman Desertification Research Station, and the soil nitrogen content and particle composition are shown in Table 1. Buckets were randomly allocated across four treatments ( 7 buckets for each treatment): three simulated and one ambient rainfall patterns. Buckets were $30 \mathrm{~cm}$ apart from each other to avoid disturbance when watering and measuring plants.

The simulated rainfall patterns were designed to represent the extremes of the local rainfall (1971-2013). The mean rain-day during the growing season from 1971-2013 was $43 \mathrm{~d}$, and the 

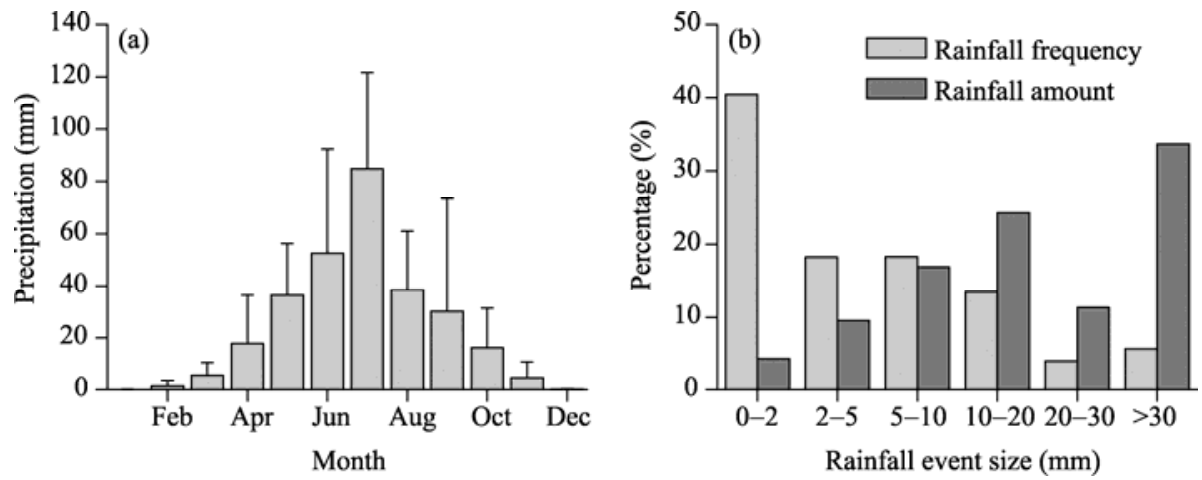

Fig. 1 Precipitation characteristics in the Naiman Desertification Research Station from 1971 to 2013. (a) Monthly precipitation; (b) percentage of rainfall frequency and amount to the total under different rainfall event sizes during the growing season. Bars mean standard errors.

Table 1 Soil properties of experimental field (mean $\pm \mathrm{SE})$

\begin{tabular}{ccccccc}
\hline \multirow{2}{*}{$\begin{array}{c}\text { Soil nitrogen content } \\
(\mathrm{g} / \mathrm{kg})\end{array}$} & $>0.5 \mathrm{~mm}$ & $0.25-0.5 \mathrm{~mm}$ & $0.10-0.25 \mathrm{~mm}$ & $0.05-0.10 \mathrm{~mm}$ & $<0.05 \mathrm{~mm}$ \\
\cline { 2 - 6 } & $0.70 \pm 0.09$ & $49.4 \pm 1.24$ & $47.73 \pm 0.97$ & $1.41 \pm 0.15$ & $0.76 \pm 0.23$ \\
\hline $0.13 \pm 0.01$ & & \multicolumn{5}{c}{ Soil particle composition $(\%)$} \\
\hline
\end{tabular}

rain days of $\geq 2, \geq 5$ and $\geq 10 \mathrm{~mm}$ were $25.6,17.8$ and $9.9 \mathrm{~d}$, respectively. For closing to the distribution of rainfall under ambient conditions, we calculated the daily rainfall amount and probability of daily rainfall $\geq 2, \geq 5$ and $\geq 10 \mathrm{~mm}$ from 1 May to 8 August, and then simulated the rainfall patterns by using Eqs. 1 and 2. $P_{i}$ in Eq. 1 represents the probability of daily rainfall, for example, $\geq 2 \mathrm{~mm}$ on the $i^{\text {th }}$ day. We set $P$ as the probability of $\geq 2 \mathrm{~mm}$ rainfall event occurring at least once during $n$ days, which was calculated by Eq. 1 .

$$
P=1-\prod_{i=1}^{n}\left(1-P_{i}\right) \text {. }
$$

A rainfall event of $\geq 2 \mathrm{~mm}$ was simulated on the first day when $P \geq 95 \%$, and then the amount of rainfall $(R)$ was calculated by using Eq. 2 .

$$
R=\sum_{i=1}^{n} r_{i}
$$

Where, $r_{i}$ represents the long-term mean daily rainfall on the $i^{\text {th }}$ day. Then, we started on the $(i+1)^{\text {th }}$ day using the same principle. Finally, we obtained the F-S rainfall pattern (Fig. 2a). Moreover, when we set $P$ as the probability of $\geq 5$ and $\geq 10 \mathrm{~mm}$ occurring at least once during $n$ days, we obtained the M-M (Fig. 2b) and I-L (Fig. 2c) rainfall patterns, respectively.

The long-term mean annual amount of rain from 1 May to 8 August (experimental period) is $217.6 \mathrm{~mm}$. In this study, the total was kept constant and assigned in the three simulated rainfall patterns: (1) 26 small rainfall events ranging from 4.3 to $13.6 \mathrm{~mm}$ (F-S; Fig. 2a); (2) 17 events ranging from 8.3 to $16.8 \mathrm{~mm}$ (M-M; Fig. 2b); and (3) 10 rainfall events ranging from 18.6 to 26.3 $\mathrm{mm}$ (I-L; Fig. 2c). The mean event size was $8.37,12.80$ and $21.76 \mathrm{~mm}$ for F-S, M-M and I-L rainfall patterns, respectively. In 2014, the total rainfall amount under ambient conditions during the experiment was $194.8 \mathrm{~mm}$, and consisted of 9 rainfall events ranging from 4.3 to $54.8 \mathrm{~mm}$ with a mean value of $21.6 \mathrm{~mm}$ (Fig. 2d). Water for the simulated rainfall in this experiment was collected from ambient rainfall with plastic buckets outside of the rain shelter, and stored in a cool dry place.

\subsection{Measurements and data analysis}

Plant characteristics, including plant cover, plant height, plant individual and species number in each bucket were measured on 22 May, 10 June, 30 June, 20 July and 8 August. The aboveground biomass (AGB) in each bucket was harvested on 8 August, and all individuals were classified by species. The roots were collected with soils at different soil depths (i.e. 0-10, 10-20 and 20-40 
$\mathrm{cm}$ ) and washed with tap water. Then, all plant samples were oven-dried at $80^{\circ} \mathrm{C}$ for $48 \mathrm{~h}$ and weighed. Shannon-Wiener diversity index was used to indicate the biological diversity (Shannon and Wiener, 1949). Air and soil temperature data were obtained from an automatic meteorological station of the Naiman Desertification Research Station, which were measured hourly by dry and wet bulb thermometer and ground-thermometer, respectively. Soil temperature was measured at depths of $0,5,10,20$ and $40 \mathrm{~cm}$.

All variables (i.e. AGB, BGB (belowground biomass), plant height, plant cover, plant individual number, species number and Shannon-Wiener index) were analyzed as a function of treatments (mean rainfall size effect) using one-way ANOVA with SPSS 19.0 software (SPSS, Chicago, IL, USA). When the ANOVA results were significant, we compared the mean values using the least significant difference (LSD) test.
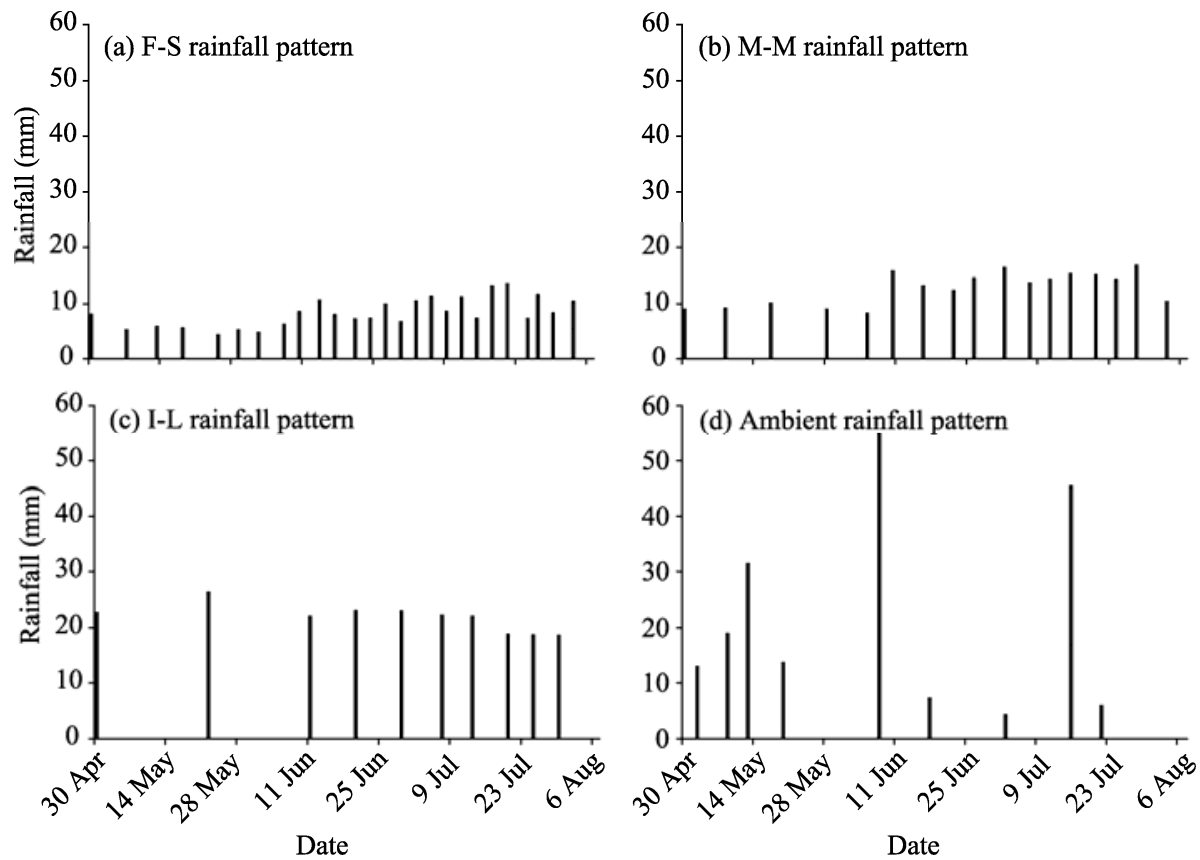

Fig. 2 Distribution of simulated (a-c) and ambient (d) rainfall events during the growing season of 2014

\section{Results}

\subsection{Soil temperature}

During this experiment, air temperature ranged from $8.15^{\circ} \mathrm{C}$ (on 2 May) to $29.95^{\circ} \mathrm{C}$ (on 31 May), with a mean value of $20.61^{\circ} \mathrm{C}$ and an intermittent decrease to $13.23^{\circ} \mathrm{C}$ (on 7 June) and increase to $23.67^{\circ} \mathrm{C}$ (on 15 June) (Fig. 3a). The mean air temperature from 15 June to 8 August was $23.64^{\circ} \mathrm{C}$ with low coefficient of variation $(9.35 \%)$. Soil temperature was influenced by both air temperature and soil depth. Specifically, during the growing season, soil temperature significantly higher in the upper soil depths than in the deeper depths, and decreased significantly with increasing soil depth (Fig. 3b).

\subsection{Characteristics of plant growth}

Rainfall patterns had important effects on plant cover, plant height, individual number, species number and Shannon-Wiener diversity index $(P<0.05$; Fig. 4). Compared to F-S rainfall pattern, plant cover, plant height and individual number significantly increased under I-L rainfall patterns. Plant cover under I-L rainfall pattern was much higher than those under F-S and M-M rainfall patterns starting on 10 June, and the cover under F-S rainfall pattern decreased starting on 20 July.

Plant height increased with increasing time under all rainfall patterns, with a low increasing rate in May and August and a fast increasing rate in June and July. Plant height under I-L rainfall 
pattern was higher than those under F-S and M-M rainfall patterns. Compared to F-S rainfall pattern, plant individual number increased significantly under I-L rainfall pattern. Species number exhibited an increase trend over time, and it was much higher under I-L rainfall pattern than under F-S rainfall pattern. Similarly, the Shannon-Wiener diversity index under I-L rainfall pattern was much higher than that under F-S rainfall pattern $(P<0.05)$. It decreased until 10 June and then increased under all rainfall patterns (except for the decrease under F-S rainfall pattern starting on 30 June). Plant cover, plant height and individual number were higher under ambient rainfall pattern than under the three simulated rainfall patterns. Species number and Shannon-Wiener diversity index were higher under ambient rainfall pattern than under F-S rainfall pattern.
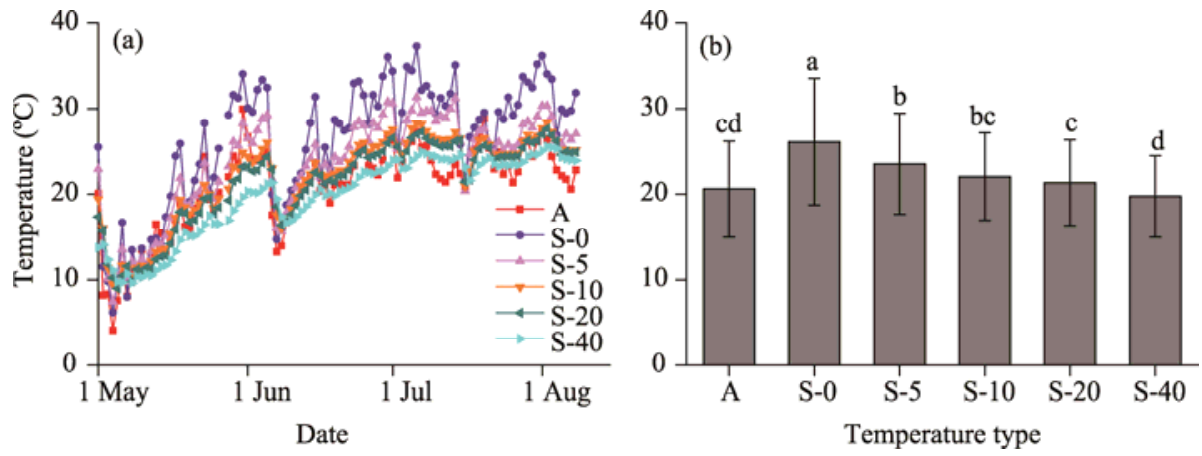

Fig. 3 Variations (a) and mean values (b) of air and soil temperatures during the growing season of 2014. A represents the air temperature; S-0, S-5, S-10, S-20 and S-40 represent soil temperature at depths of 0, 5, 10, 20 and $40 \mathrm{~cm}$, respectively. Bars mean standard errors. Different lowercase letters indicate significant differences among different temperature types $(P<0.05)$.
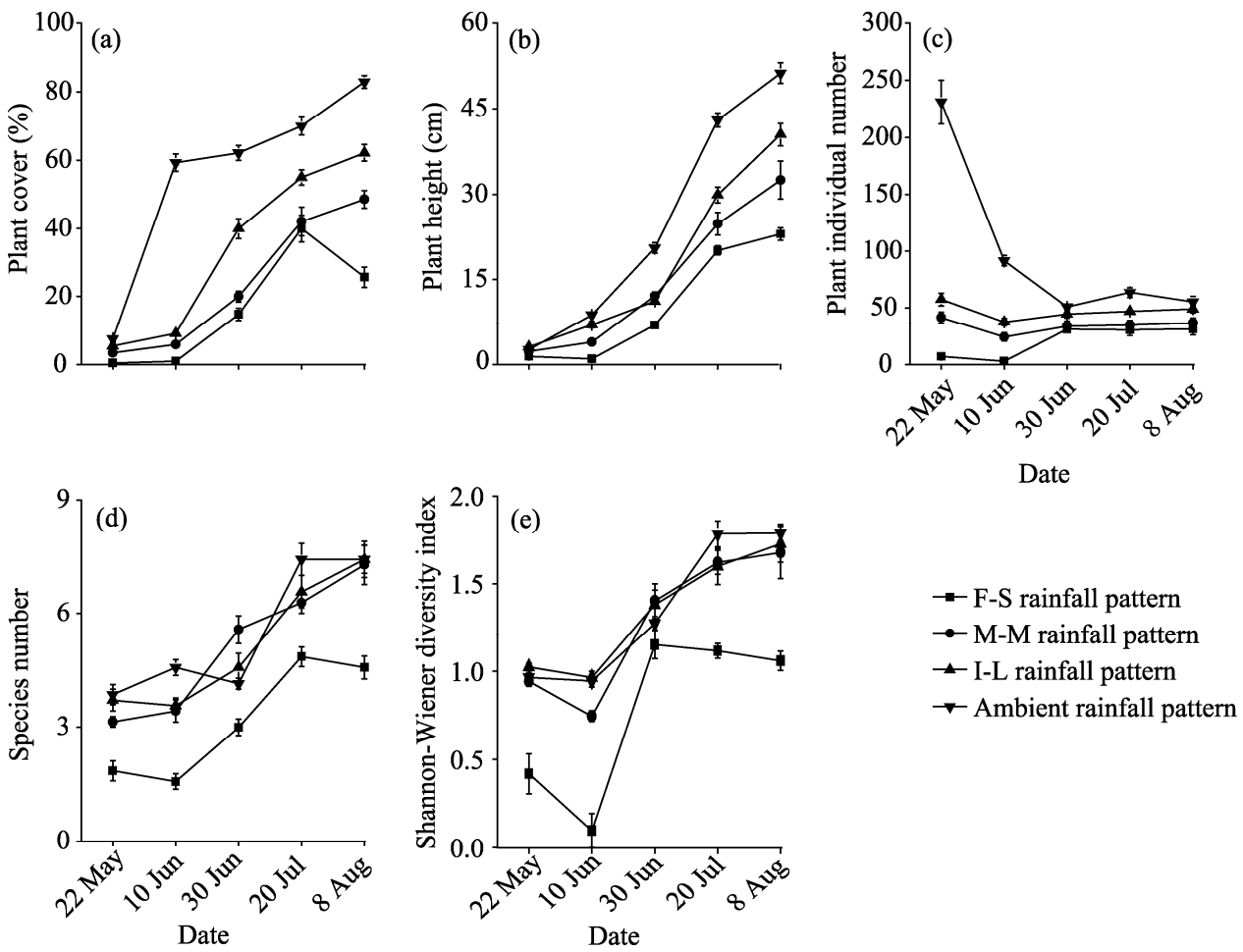

Fig. 4 Characteristics of plant growth under all rainfall patterns during the growing season of 2014. Bars mean standard errors.

\subsection{Biomass and rainfall use efficiency (RUE)}




\subsubsection{Aboveground and belowground biomass and RUE}

Rainfall patterns had important effects on biomass and RUE (Fig. 5). AGB increased from 106.8 $\mathrm{g} / \mathrm{m}^{2}$ under F-S rainfall pattern to $255.3 \mathrm{~g} / \mathrm{m}^{2}$ under I-L rainfall pattern, and BGB increased from 69.1 under F-S rainfall pattern to $118.7 \mathrm{~g} / \mathrm{m}^{2}$ under I-L rainfall pattern (Fig. 5a). The ratio of BGB to AGB under F-S rainfall pattern was 0.66 , which was significantly higher than those under M-M $(0.55)$ and I-L $(0.47)$ rainfall patterns $(P<0.05)$. The AGB and RUE were 2.4 and 3.1 times more under ambient rainfall pattern than under I-L rainfall pattern, respectively $(P<0.05)$. However, BGB exhibited no significant differences between I-L and ambient rainfall patterns $(P>0.05)$. The value of RUE increased from $0.49 \mathrm{~g} /\left(\mathrm{m}^{2} \cdot \mathrm{mm}\right)$ under F-S rainfall pattern to $1.17 \mathrm{~g} /\left(\mathrm{m}^{2} \cdot \mathrm{mm}\right)$ under I-L rainfall pattern (Fig. 5b).
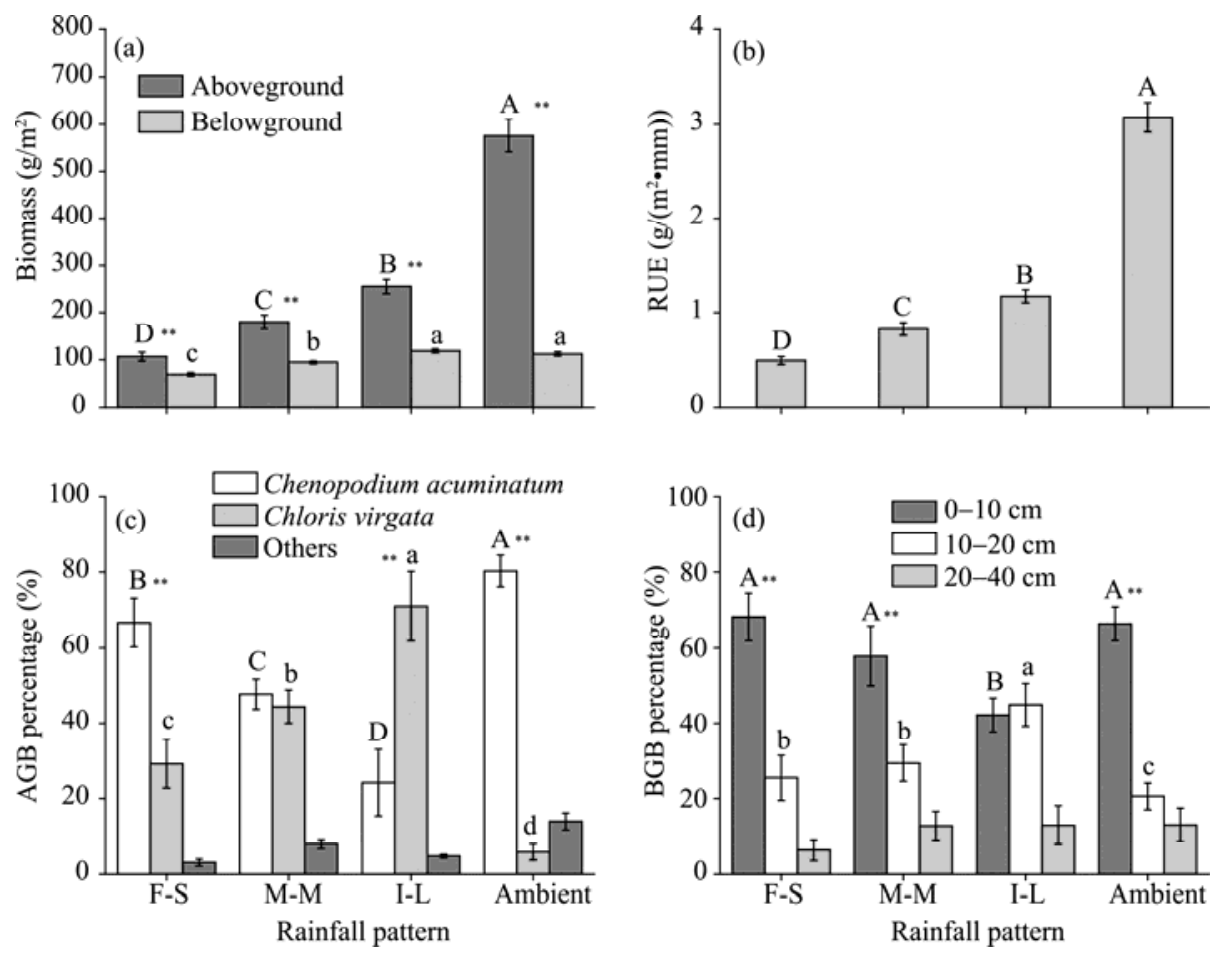

Fig. 5 Biomass (a), RUE (b), percentage of species biomass to the total AGB (c) and percentage of BGB at different soil depths to the total BGB (d) under all rainfall patterns. Bars mean standard errors. AGB, aboveground biomass; BGB, belowground biomass; RUE, rainfall use efficiency. Different capital and lowercase letters indicate significant differences of different variables among rainfall patterns $(P<0.05) .{ }^{* *}$ indicates significant difference for the same rainfall pattern at $P<0.05$ level.

\subsubsection{Species biomass}

Biomass of Chloris virgata and Chenopodium acuminatum contributed more than $85 \%$ of the total AGB under all rainfall patterns (Fig. 5c). For the three simulated rainfall patterns, with increasing size of rainfall event, the percentage contribution of Chloris virgata to the total AGB increased, while that of Chenopodium acuminatum decreased $(P<0.05)$. For example, under F-S rainfall pattern, the percentage of Chenopodium acuminatum occupied $66.68 \%$ of the total AGB, which was significantly higher than that of Chloris virgata $(29.97 \%)(P<0.05)$. Under M-M rainfall pattern, there was no significant difference between biomass percentages of these two species. The percentage of Chloris virgata to the total AGB under I-L rainfall pattern was $71.06 \%$, while that of Chenopodium acuminatum was only $24.23 \%$. Moreover, under ambient rainfall pattern, the percentage of Chenopodium acuminatum to the total AGB was $80.30 \%$, which was higher than those under the three simulated rainfall patterns $(P<0.01)$.

\subsubsection{Vertical distribution of BGB}

In this experiment, more than $85 \%$ of root biomass was distributed in the $0-20 \mathrm{~cm}$ soil layer (Fig. 
5d). The percentage contribution of BGB in the $0-20 \mathrm{~cm}$ soil layer to the total BGB under F-S rainfall pattern was $93.71 \%$, which was higher than those under the three rainfall patterns. The contribution of BGB in different soil layers to the total BGB decreased with increasing soil depth under all rainfall patterns except the I-L. Under I-L rainfall pattern, there was no significant differences of BGB in the $0-10$ and $10-20 \mathrm{~cm}$ soil layers $(P>0.05)$. Under the three simulated rainfall patterns, the contribution of BGB in the $0-10 \mathrm{~cm}$ soil layer to the total BGB decreased from $68.2 \%$ (under F-S rainfall pattern) to $42.2 \%$ (under I-L rainfall pattern). Moreover, under ambient rainfall pattern, the percentage contribution of BGB in the $0-10 \mathrm{~cm}$ soil layer to the total BGB was $66.4 \%$, while that in the $10-20 \mathrm{~cm}$ soil layer only accounted for $22.1 \%$ to the total.

\section{Discussions}

At large spatial scales, mean annual precipitation is considered to be the main driving factor in the variation of biomass in grasslands (Yang et al., 2008; Hsu et al., 2012), but it is not the driving factor in the variation of AGB at regional scales (Zhou et al., 2009). Annual precipitation can account for $39 \%$ of the inter-annual variability in AGB in semi-arid grasslands (Hsu and Adler, 2014). In this study, we found that rainfall patterns had significant effects on biomass, plant cover, species diversity and vertical distribution of BGB. Our study also supported the results of Swemmer et al. (2007) that in grassland, rainfall distribution (including rainfall event size and frequency, and length of dry interval) during the growing season played a more prominent role than the total amount of rainfall. This was because rainfall distribution directly influenced the quantity of available water for plant uptake (Loik et al., 2004). In 2014, we manipulated the number of rainfall events (while holding the total rainfall amount to be constant) and determined that large rainfall with low frequency produced higher biomass, plant cover and species diversity for the annual plants than small rainfall with high frequency. Our goal was to distinguish the relative importance of rainfall event size or frequency and predict the potential responses of annual plants to the changes of rainfall regime in semi-arid regions.

\subsection{Effects of large versus small rainfall events on annual plants}

In semi-arid regions, the spatial and temporal availability of soil moisture for biological processes is directly linked to the size and frequency of rainfall event (Huxman et al., 2004). Current rainfall regimes is dominated by small rainfall with high frequency, which only wets the uppermost soil layers and evaporates rapidly (Sala and Lauenorth, 1982; Lauenroth et al., 2014). In contrast, large rainfall with low frequency recharges and increases soil moisture at deeper depths (Heisler-White et al., 2008; Thomey et al., 2011). Although almost all water from large rainfall events is also eventually lost to the atmosphere via evaporation and transpiration, the large rainfall events are more biologically effective than the small ones due to the lower soil temperature in the deeper soil layers than in the upper soil layers. Our hypothesis that the large rainfall with low frequency would result in higher biomass was fully confirmed.

In this study, under a constant amount of total rainfall, changing the size and frequency of rainfall events increased the total AGB from $106.8 \mathrm{~g} / \mathrm{m}^{2}$ under F-S rainfall pattern to $255.3 \mathrm{~g} / \mathrm{m}^{2}$ under I-L pattern, and increased the total BGB from 69.06 to $118.71 \mathrm{~g} / \mathrm{m}^{2}$. These results were in agreement with some previous studies (Schwinning and Sala, 2004; Heisler-White et al., 2008, 2009). Also, the larger rainfall produced higher plant cover, plant height, plant number and species diversity than the smaller one. The percentage contribution of root biomass at deeper soil layers to the total BGB increased with an increase of mean rainfall event size or a decrease of rainfall event number, which may be attributed to an increase in water availability at deeper soil layers (Huxman et al., 2004). The percentage contribution of Chenopodium acuminatum to the total AGB decreased while that of Chloris virgata increased with an increase in the mean rainfall event size, indicating the large rainfall with low frequency may favor the growth of Chloris virgata.

However, our results contrasted the findings of Miranda et al. (2009), who found that annuals in semi-arid regions did not exhibit significant responses in productivity and species diversity to 
the changes of rainfall patterns in the short-term (Miranda et al., 2009). This may be due to the differences in local climate, soil and vegetation types, which may amplify or buffer the impacts of changed rainfall patterns (Grime et al., 2008; Heisler-White et al., 2009; Fernandez-Going et al., 2012). The study site of Miranda et al. (2009) was located on a coastal sand dune, where mean annual precipitation was $200-250 \mathrm{~mm}$ and annual mean temperature was $17^{\circ} \mathrm{C}-19^{\circ} \mathrm{C}$. Thus, annual plants may have a stronger capacity for adaptation to rainfall variability due to the lower annual precipitation and higher annual mean temperature.

\subsection{Effects of uniform versus stochastic rainfall patterns on annual plants}

Under ambient conditions, rainfall events are rarely evenly distributed in amount and time (Loik et al., 2004), and it is unlikely that they should be so in future. In our experiment, the rainfall under ambient conditions was $194.8 \mathrm{~mm}$, which was close to the long-term mean $(217.6 \mathrm{~mm})$, and the mean event size $(21.64 \mathrm{~mm})$ was almost equal to that under I-L rainfall pattern $(21.76$ $\mathrm{mm}$ ). However, there were significant differences in the AGB, plant cover and plant individual number under different rainfall patterns. The RUE under ambient rainfall pattern was 2.6 times more than that under I-L rainfall pattern. These differences can be attributed to the larger variation in event size and timing of rainfall rather than to the total amount and number of rainfall events.

Under ambient conditions, the size of rainfall ranged from 4.3 to $54.8 \mathrm{~mm}$ (including 3 events of $>30 \mathrm{~mm}$ ), which may result in a higher RUE compared to I-L rainfall pattern. Also, under ambient rainfall pattern, $77-\mathrm{mm}$ rain fell in the first 20 days of the growing season. This was much higher than the amount recorded during the growing season from 1971 to 2012 (21.8 mm). These large rainfalls significantly increased plant individual number and plant cover (Fig. 4). Higher vegetation cover can increase RUE by decreasing evaporation from soil (Hu et al., 2007). Under ambient rainfall pattern, the percentage contribution of Chenopodium acuminatum to the total AGB was more than that of Chloris virgata. Due to the different plant physiologyical and phenological characteristics, the variability of rainfall in space, time or size may influence the competitive advantage and dominance of plant species (Chesson et al., 2004; Bansal et al., 2014).

Consequently, our results indicated that the modification of rainfall regimes may favor certain plant species rather than all species. This supported the results of McKinney and Lockwood (1999), who hypothesized that climate changes may increase the dominance of a few species, which can accommodate a broad range of environmental variability. Rainfall regime changes have the capacity to alter the patterns of resource availability and acquisition, influence competitive interactions, and lead to community change for terrestrial ecosystems (Knapp et al., 2008).

\section{Conclusions}

Despite of the global-scale prediction that rainfall variability will increase in future, potential ecological consequences of these changes only received minor attention compared with those related to elevated atmospheric $\mathrm{CO}_{2}$ and global warming. More research is necessary to understand the potential responses of plants to the changed precipitation regimes. Our results indicated that the rainfall patterns, independent of the amount of total rainfall, play an important role in the biomass, species diversity and species composition of annual plants in Horqin Sandy Land. A rainfall regime with intensifying rainfall events may be likely to increase biomass and influence species diversity and composition of sandy grasslands dominated by annual plant species.

\section{Acknowledgements}

This study was supported by the Strategic Leading Science and Technology Projects of Chinese Academy of Sciences (XDA05050201-04-01), the National Natural Science Foundation of China $(41371053,31500369)$ and the 'One Hundred Talent' Program of Chinese Academy of Sciences (Y451H31001). Authors thank all the technicians of Naiman Desertification Research Station, Chinese Academy of Sciences for their help in field work. 
We also thank anonymous reviewers for providing helpful comments on this manuscript.

\section{References}

Allan R P, Soden B J. 2008. Atmospheric warming and the amplification of precipitation extremes. Science, 321(5895): 1481-1484.

Bansal S, James J J, Sheley R L. 2014. The effects of precipitation and soil type on three invasive annual grasses in the western United States. Journal of Arid Environments, 104: 38-42.

Cheng X L, An S Q, Li B, et al. 2006. Summer rain pulse size and rainwater uptake by three dominant desert plants in a desertified grassland ecosystem in northwestern China. Plant Ecology, 184(1): 1-12.

Chesson P, Gebauer R L E, Schwinning S, et al. 2004. Resource pulses, species interactions, and diversity maintenance in arid and semi-arid environments. Oecologia, 141(2): 236-253.

Cleland E E, Collins S L, Dickson T L, et al. 2013. Sensitivity of grassland plant community composition to spatial vs. temporal variation in precipitation. Ecology, 94(8): 1687-1696.

Fay P A, Carlisle J D, Knapp A K, et al. 2003. Productivity responses to altered rainfall patterns in a $\mathrm{C}_{4}$-dominated grassland. Oecologia, 137(2): 245-251.

Fernandez-Going B M, Anacker B L, Harrison S P. 2012. Temporal variability in California grasslands: soil type and species functional traits mediate response to precipitation. Ecology, 93(9): 2104-2114.

Grime J P, Fridley J D, Askew A P, et al. 2008. Long-term resistance to simulated climate change in an infertile grassland. Proceedings of the National Academy of Sciences of the United States of America, 105(29): 10028-10032.

Heisler-White J L, Knapp A K, Kelly E F. 2008. Increasing precipitation event size increases aboveground net primary productivity in a semi-arid grassland. Oecologia, 158(1): 129-140.

Heisler-White J L, Blair J M, Kelly E F, et al. 2009. Contingent productivity responses to more extreme rainfall regimes across a grassland biome. Global Change Biology, 15(12): 2894-2904.

Hsu J S, Powell J, Adler P B. 2012. Sensitivity of mean annual primary production to precipitation. Global Change Biology, 18(7): 2246-2255.

Hsu J S, Adler P B. 2014. Anticipating changes in variability of grassland production due to increases in interannual precipitation variability. Ecosphere, 5(5), doi: 10.1890/ES13-00210.1.

Hu Z M, Fan J W, Zhong H P, et al. 2007. Spatiotemporal dynamics of aboveground primary productivity along a precipitation gradient in Chinese temperate grassland. Science in China Series D: Earth Sciences, 50(5): 754-764.

Huxman T E, Snyder K A, Tissue D, et al. 2004. Precipitation pulses and carbon fluxes in semiarid and arid ecosystems. Oecologia, 141(2): 254-268.

IPCC. 2007. Climate Change 2007: Mitigation of Climate Change: Contribution of Working Group III to the Fourth Assessment Report of the IPCC. Cambridge: Cambridge University Press.

Knapp A K, Fay P A, Blair J M, et al. 2002. Rainfall variability, carbon cycling, and plant species diversity in a mesic grassland. Science, 298(5601): 2202-2205.

Knapp A K, Beier C, Briske D D, et al. 2008. Consequences of more extreme precipitation regimes for terrestrial ecosystems. Bioscience, 58(9): 811-821.

Lauenroth W K, Bradford J B. 2009. Ecohydrology of dry regions of the United States: precipitation pulses and intra-seasonal drought. Ecohydrology, 2(2): 173-181.

Lauenroth W K, Schlaepfer D R, Bradford J B. 2014. Ecohydrology of dry regions: Storage versus pulse soil water dynamics. Ecosystems, 17(8): 1469-1479.

Loik M E, Breshears D D, Lauenroth W K, et al. 2004. A multi-scale perspective of water pulses in dryland ecosystems: climatology and ecohydrology of the western USA. Oecologia, 141(2): 269-281.

McKinney M L, Lockwood J L. 1999. Biotic homogenization: a few winners replacing many losers in the next mass extinction. Trends in Ecology \& Evolution, 14(11): 450-453.

Miranda J D, Padilla F M, Lázaro R, et al. 2009. Do changes in rainfall patterns affect semiarid annual plant communities? Journal of Vegetation Sciences, 20(2): 269-276.

Noy-Meir I. 1973. Desert ecosystems: environment and producers. Annual Review of Ecology and Systematics, 4(1): 25-51.

Sala O E, Lauenroth W K, Parton W J, et al. 1981. Water status of soil and vegetation in a shortgrass steppe. Oecologia, 48(3): $327-331$.

Sala O E, Lauenroth W K. 1982. Small rainfall events: an ecological role in semiarid regions. Oecologia, 53(3): 301-304.

Schwinning S, Sala O E. 2004. Hierarchy of responses to resource pulses in arid and semi-arid ecosystems. Oecologia, 141(2): 
211-220.

Shannon C E, Wiener W J. 1949. The Mathematical Theory of Communication. Urbana: University of Illinois Press.

Su Y Z, Li Y L, Zhao H L. 2006. Soil properties and their spatial pattern in a degraded sandy grassland under post-grazing restoration, Inner Mongolia, northern China. Biogeochemistry, 79(3): 297-314.

Swemmer A M, Knapp A K, Snyman H A. 2007. Intra-seasonal precipitation patterns and above-ground productivity in three perennial grasslands. Journal of Ecology, 95(4): 780-788.

Thomey M L, Collins S L, Vargas R, et al. 2011. Effect of precipitation variability on net primary production and soil respiration in a Chihuahuan desert grassland. Global Change Biology, 17(4): 1505-1515.

Weltzin J F, Loik M E, Schwinning S, et al. 2003. Assessing the response of terrestrial ecosystems to potential changes in precipitation. Bioscience, 53(10): 941-952.

Yang Y H, Fang J Y, Ma W H, et al. 2008. Relationship between variability in aboveground net primary production and precipitation in global grasslands. Geophysical Research Letters, 35(23): L23710, doi: 10.1029/2008GL035408.

Zhou X H, Talley M, Luo Y Q. 2009. Biomass, litter, and soil respiration along a precipitation gradient in southern Great Plains, USA. Ecosystems, 12(8): 1369-1380.

Zhu Z D, Chen G T. 1994. The Sandy Desertification in China. Beijing: Science Press. (in Chinese) 